\title{
Gamma Dose-Dependence of Calcium Phosphate Growth on DFDBA Subsequent to SBF Immersion
}

\author{
Gehan T.El-Bassyouni ${ }^{1}$, Wafa I. Abdel-Fattah ${ }^{1}$ and \\ Mohamed I. El-Gohary ${ }^{2}$ \\ ${ }^{1}$ Ceramics Department, National Research Center, Cairo, Egypt \\ ${ }^{2}$ Biophysics Department., El-Azhar University, Egypt
}

The simulated body fluid (SBF) induced epitaxial calcium phosphate growth on demineralized freeze dried bone allograft (DFDBA) xenogeneic bone matrices as a function of ${ }^{60} \mathrm{Co}$-gamma sterilization with single shot technique of 15,25, 30 and $40 \mathrm{KGy}$. Surface morphology by Scanning electron microscope (SEM) supplemented by EDAX as well as FT-IR analyses were conducted for the solids pre-, post-irradiation and post-immersion in SBF up to 72 hours. The ability of the tissues to form bone was predicted through $\mathrm{Ca}$ and $i P$ ions measurements in SBF as a function of immersing times at each applied gammadose. The epitaxial growth of octacalcium phosphate (OCP) with rose like morphology characteristically defined $15 \mathrm{KGy}$ as the most effective gamma dose on inducing biolayer formation. FT-IR analyses correlated precisely with the degree of denaturation of protein with $30 \mathrm{KGy}$ and the structure reverted to a state similar to pre-irradiation with $40 \mathrm{KGy}$.

\section{Introduction:}

Various ways are used for sterilizing biomaterials such as steam sterilization, gaseous ethylene oxide (EO) or ${ }^{60} \mathrm{Co}$-gamma-rays[1]. Driedzic et al. [2] adopted the sterilization of bone allograft using ${ }^{60} \mathrm{Co}$ irradiation, since it can make the graft sterilized with the least side effect on collagen, bone matrix protein. The effect of irradiation on solids might cause displacement and replacement collisions. When radiant energy acts on a material, profound changes may occur in its structure affecting its mechanical strength and optical as well as electrical properties. However, gamma irradiation is the most widely used for sterilization of biomaterials due to its efficient penetration power. However, the irradiation of an osteoinductive demineralized bone (DB) implant resulted in a smaller residual bone matrix that induced less amount of new normal bone [3]. 
Demineralized freeze dried bone allograft (DFDBA) is the most widely used allograft material in periodontics due to its availability, safety and combined osteoinductive and osteoconductive properties [4]. Gamma rays were reported in doses of $25 \mathrm{KGy}$ in the standards for medical devices [5]. Higher doses of ionizing radiation (above 40-50 KGy) may evoke numerous physiochemical changes in tissue allograft, e.g. induction of free radicals , which may decrease the biological quality of bone e.g. osteoinductive capacity of bone allograft [6]. Bozarth et al. [7] concluded that the $30 \mathrm{KGy}$ dose yielded $57.6 \%$ collagen denaturation and an increase in susceptibility to fracture by $64 \%$ besides complete elimination of post-yields deformation.

The formation of bone like apatite on the surface of an artificial biomaterial is essential for bone bonding in the living body [8]. The aim of the present study was to differentiate between the effect of various doses of ${ }^{60} \mathrm{Co}$ gamma on changes in the structure of DFDBA pre- and post- immersion in $\mathrm{SBF}$. The aqueous media for such examination is desired to simulate that of the body fluid (SBF) $[9,10]$

\section{Materials and Methods:}

\subsection{Materials and sterilization technique:}

Bovine bone samples of particle size (250-500) $\mu \mathrm{m}$ were prepared and demineralized using $0.6 \mathrm{~N} \mathrm{HCl}$ at room temperature for 24 hours. Samples were washed and dehydrated then freeze-dried at suitable temperature. Gamma irradiation of the samples was carried out to reach separate single shots of 15 , 25, 30 and $40 \mathrm{KGy}$ using ${ }^{60}$ Cobalt.

\subsection{In-vitro Degradation:}

a) SBF preparation for immersion tests:

The SBF with ion concentrations nearly equal to those in human blood plasma (HBP) was freshly prepared by dissolving reagent-grade chemicals of $\mathrm{NaCl}, \mathrm{NaHCO}_{3}, \mathrm{KCl}, \mathrm{K}_{2} \mathrm{HPO}_{4} .3 \mathrm{H}_{2} \mathrm{O}, \mathrm{MgCl}_{2} .6 \mathrm{H}_{2} \mathrm{O}, \mathrm{CaCl}_{2}$ and $\mathrm{Na}_{2} \mathrm{SO}_{4}$ into distilled water. The $\mathrm{pH}$ of the solution was adjusted to 7.4 at $37^{\circ} \mathrm{C}$. This fluid was reported to satisfactorily induce apatite formation on the surfaces of various kinds of bioactive materials in vivo [11].

b) Simulated Body Fluid (SBF) Biochemical Analysis:

The concentration of calcium $\left(\mathrm{Ca}^{2+}\right)$ and inorganic phosphorus (iP) ions released in simulated body fluid SBF after immersing the samples for 5 
sequential periods up to 72 hours were followed up by spectrophotometer (6100, Type $M / 29$, Jenway, UK) using relevant biochemical kits[12]. The ratios of weight of samples/volume of immersing SBF solution were kept constant at room temperature without agitation.

\subsection{Structural Characterization:}

a) Scanning Electron Microscope (SEM):

The variation in the microstructure of the bone powder pre -, postirradiation and post- immersion were examined using SEM (Joel, Japan TSU. $\mathrm{T}-20$ and $19 \mathrm{KeV}$ ) supplemented with X-ray unit (EDAX).

b) Fourier transform-infrared spectral analysis (FT-IR).

The analyses were performed semi quantitatively for DFDBA powders pre, post $\gamma$-sterilization and post-immersion in SBF using (FT-IR-300E JASCO co-operation, Japan). It is supposed that any reduced or increased optical density (O.D.) calculated by applying the Beer-Lambert's law could indicate dissolution or precipitation of the specific groups within the structure respectively.

\section{Results and Discussion}

\subsection{Biochemical Assessments of the media:}

\subsubsection{SBF immersion media:}

a) DFDBA un-irradiated immersion media

$\mathrm{The} \mathrm{Ca}^{2+}$ and iP ion concentrations are listed in Table (1). It is clear that DFDBA tissue adsorbs $\mathrm{Ca}^{2+}$ at all immersion periods. The highest adsorption is recorded at 6 hours. The $\mathrm{Ca}^{2+}$ reduced values are in favor of the biolayer deposition. The values recorded for iP ions in SBF proved dissolution since all values are higher than those of control SBF. This could be attributed to some inorganic remnant ions of the demineralization process. The values recorded for $\mathrm{iP}$ at all immersion times are almost 4 times those measured in SBF except at 6 hours immersion, where it is less than double the value of SBF. Consequently, we acknowledge the immersion period of 6 hours for the biolayer deposition. 
Table (1): $\mathrm{Ca}^{2+}(\mathrm{mg} / 100 \mathrm{ml})$ and iP (mmol/L) ion concentrations subsequent to immersion in SBF of DFDBA pre-and post-irradiation using various doses of gamma rays.

\begin{tabular}{|c|c|c|c|c|c|c|c|c|c|c|c|}
\hline \multirow{3}{*}{ Samples } & \multirow{3}{*}{$\begin{array}{c}\text { Dose } \\
\text { (KGy } \\
\text { ) }\end{array}$} & \multicolumn{10}{|c|}{ Time of immersion (hours) } \\
\hline & & \multicolumn{2}{|c|}{3} & \multicolumn{2}{|c|}{6} & \multicolumn{2}{|c|}{24} & \multicolumn{2}{|c|}{48} & \multicolumn{2}{|c|}{72} \\
\hline & & $\mathrm{Ca}^{2+}$ & iP & $\mathrm{Ca}^{2+}$ & iP & $\mathrm{Ca}^{2+}$ & iP & $\mathrm{Ca}^{2+}$ & iP & $\mathrm{Ca}^{2+}$ & iP \\
\hline SBF & - & 22.3 & 0.37 & 24 & 0.40 & 25 & 0.36 & 25 & 0.38 & 23.4 & 0.31 \\
\hline DFDBA & 0 & 21.6 & 1.39 & 8.8 & 0.74 & 14.5 & 1.29 & 15.15 & 1.18 & 12.68 & 1.20 \\
\hline DFDBA & 15 & 19.3 & 0.77 & 10.4 & 0.71 & 12.16 & 0.60 & 11.63 & 0.39 & 11.78 & 0.45 \\
\hline DFDBA & 25 & 22.27 & 0.92 & 8.64 & 0.84 & 12.62 & 0.50 & 12.9 & 0.38 & 11.99 & 0.41 \\
\hline DFDBA & 30 & 20.4 & 0.86 & 12.9 & 0.88 & 12.64 & 0.70 & 13.85 & 0.50 & 12.36 & 0.36 \\
\hline DFDBA & 40 & 18.9 & 0.75 & 11.4 & 0.77 & 12.8 & 0.47 & 13.5 & 0.28 & 12.2 & 0.35 \\
\hline
\end{tabular}

b) $\gamma$-irradiated DFDBA immersion media

The reduced rates of $\mathrm{Ca}^{2+}$ adsorption for all irradiated samples compared with un-irradiated one, could be attributed to the cross linking of the collagenous structure. The concentration of radiation-induced free radicals alteration and/or production of new radicals and radiolytic degradation could produce chain scission. Some cross linking can occur mainly in the post irradiation stage through the decay and coupling of the hydrogen obstruction radicals [13]. Leaching of the iP remaining in the irradiated tissue assists the hypothesis of collagen cross linking rendering the structure more tight to release ions [7]. It has to be notified that the values of iP in SBF did not follow a specific trend in parallel with increasing the dose although, comparatively highest values of iP dissolution were recorded for $\gamma-30$ SBF. This contradicts the idea of cross linking as the only factor affecting the process. At and above 24 hours higher dissolution values are following the order of $\gamma-15>\gamma-25>\gamma-$ 40. Therefore, degree of cross linking is increasing with $\gamma$-dose. Unexpectedly, the $\gamma-30$ recorded highest value at immersion time of 6,24 and 48 hours which indicates maximum defective structure with chain scission of collagen and denaturation leading to maximum release of ions.

\subsection{Structural Analysis:}

\subsubsection{Morphology of DFDBA:}

i- Un-irradiated DFDBA matrices:

The surface of the un-irradiated DFDBA sample revealed more or less homogeneous collageneous appearance with spreaded pores of various sizes (Fig. 1a). Ravaglioli and Krajewski [14] empirically deduced the chemical reaction of demineralization which could be represented as follows: 


$$
\mathrm{Ca}_{10}\left(\mathrm{PO}_{4}\right)_{6}(\mathrm{OH})_{2}+14 \mathrm{HCl} \rightarrow 7 \mathrm{CaCl}_{2}+3 \mathrm{Ca}\left(\mathrm{H}_{2} \mathrm{PO}_{4}\right)_{2}+2 \mathrm{H}_{2} \mathrm{O}
$$

As some $\mathrm{CaCO}_{3}$ could be present in biological bone a parallel reaction could be expected.

$$
\mathrm{CaCO}_{3}+2 \mathrm{HCl} \rightarrow \mathrm{CaCl}_{2}+\mathrm{CO}_{2}+\mathrm{H}_{2} \mathrm{O} \text {. }
$$

Therefore, the presence of $\mathrm{Cl}^{-}$elements in EDAX is confirmed as shown in Fig.(1f).
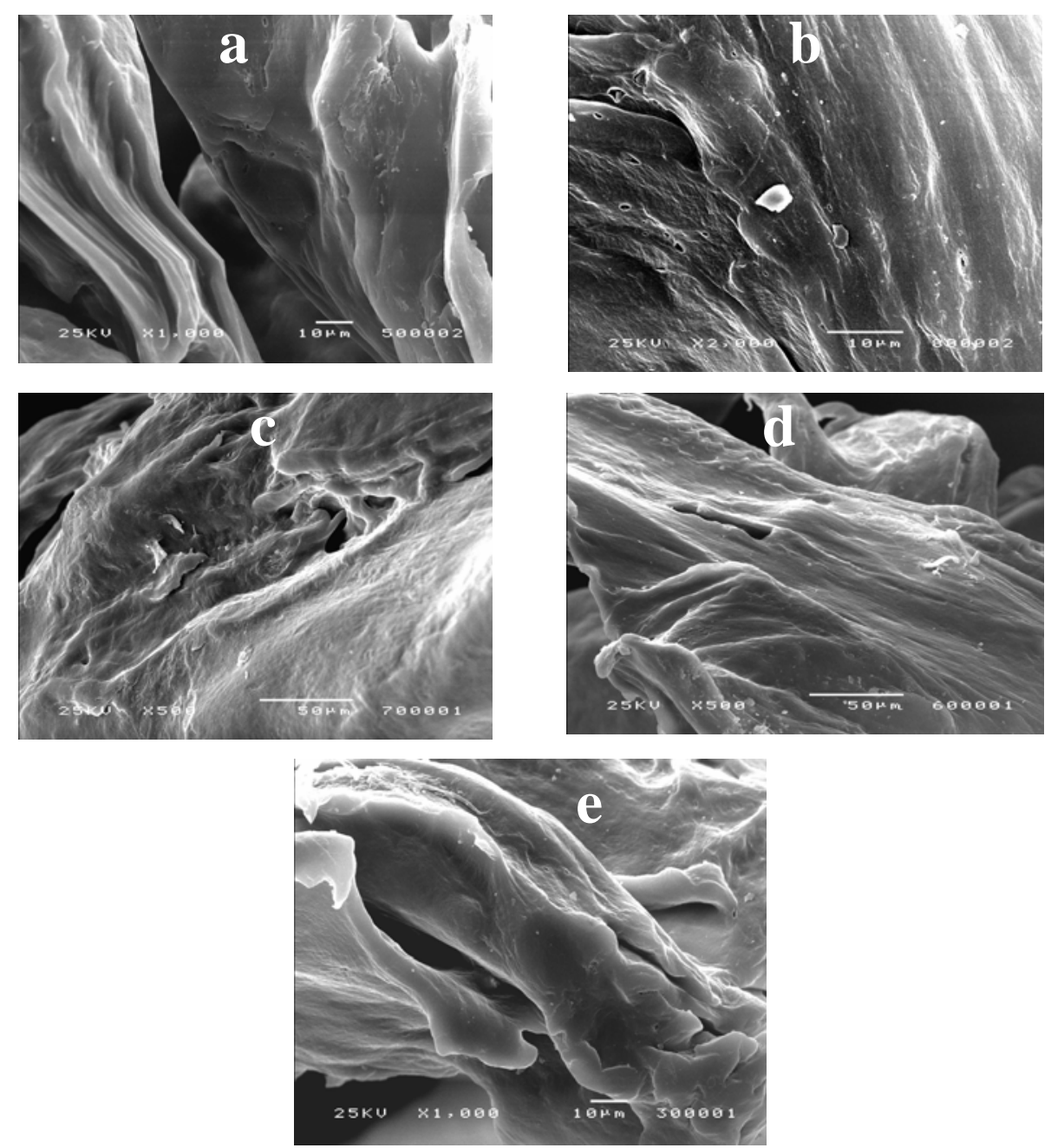

Fig. (1): Morphology evolution of pre-immersion DFDBA: a) un-irradiated ( $x=1000)$ b) $15 \mathrm{KGy}(\mathrm{x}=2000)$ c) $25 \mathrm{KGy}(\mathrm{x}=500)$ a) $30 \mathrm{KGy}(\mathrm{x}=500)$ e) $40 \mathrm{KGy}$ $(\mathrm{x}=1000)$ and $\mathrm{f})$ EDAX.

ii. $\gamma$-irradiated DFDBA 
The matrices irradiated with various $\gamma$-doses reveal dense collageneous appearance with few spreaded angular and rounded particles (Fig. 1b-e). Longitudinal and rounded closed pores can also be detected due to radiation induced defects. The corresponding EDAX of all tissues were carried out and appeared almost similar. Fig. 1f represent this relation. It revealed elements of $\mathrm{Si}, \mathrm{Cl}, \mathrm{Al}, \mathrm{Ca}, \mathrm{Fe}$ and $\mathrm{P}$ resulting from the original tissue.

iii. Immersed DFDBA matrices

Upon treatment with SBF for 72 hours (Fig. 2a) shows optically dense spherical striated globules recorded on the surface having a diameter of $3.38 \mu \mathrm{m}$.
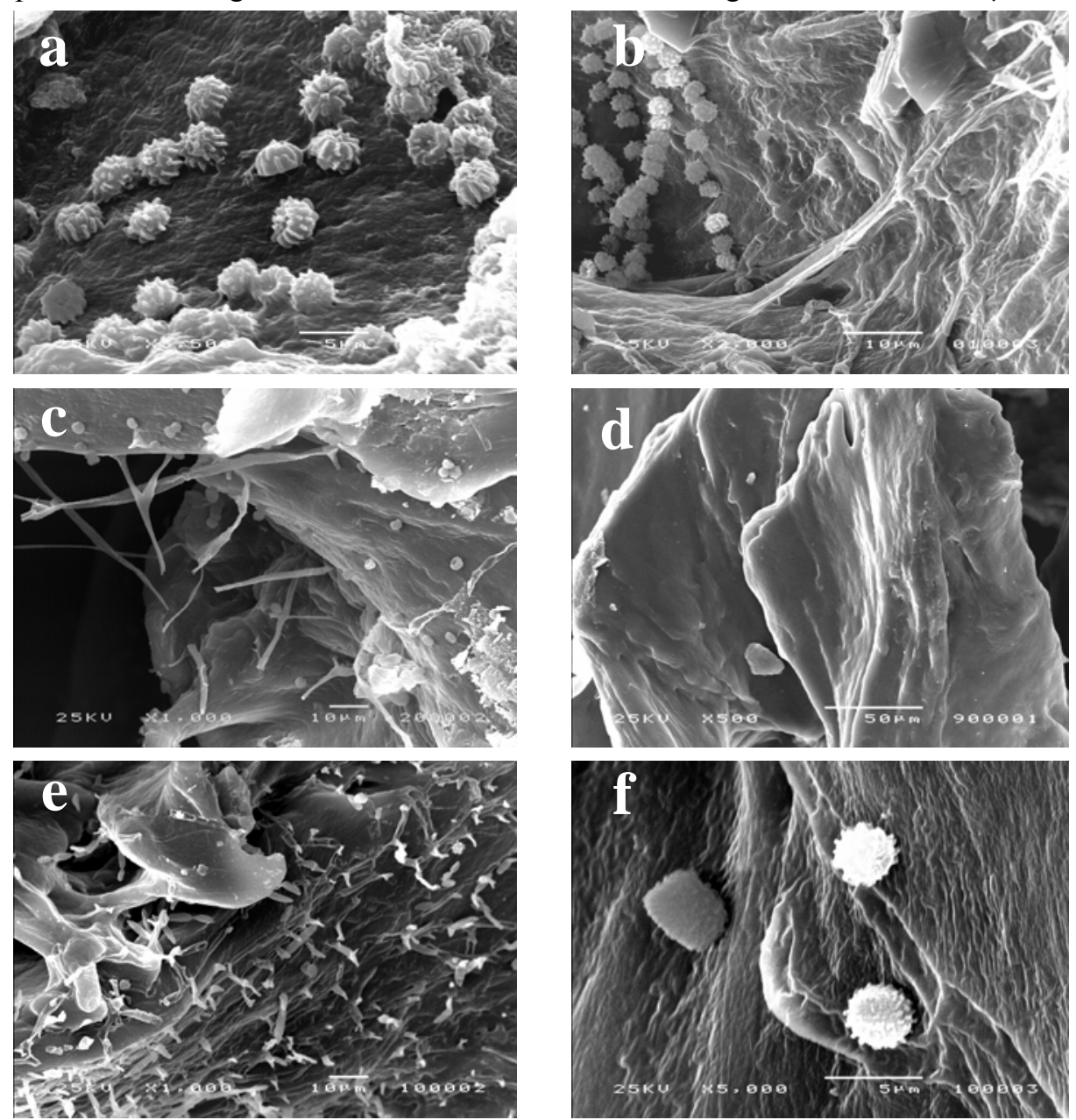

Fig. (2): Morphology evolution of post-immersion DFDBA: a) un-irradiated ( $x=1500)$ b) $15 \mathrm{KGy}(\mathrm{x}=2000)$ c) $25 \mathrm{KGy}(\mathrm{x}=1000)$ a) $30 \mathrm{KGy}(\mathrm{x}=500)$ e) $40 \mathrm{KGy}$ $(x=1000)$ and $f) 40 \mathrm{KGy}(\mathrm{x}=5000)$.

iv. $\gamma$-irradiated and immersed DFDBA. 
An initial Ca-P film and collageneous network of fibers are observed on $\gamma-15$ KGy. Several crystal plates of carbonated calcium phosphate (Fig. 2b) with secondary octacalcium phosphate (OCP) growth are detected. For the $25 \mathrm{KGy}$, the surface is covered with a network of fibers, Ca-P globules of finer size $(3.33 \mu \mathrm{m})$. Leaflets of OCP and some other higher optically dense amorphous areas could be seen (Fig. 2c)

The DFDBA $\gamma$-30 (Fig. 2d) revealed dense semi opaque matrix with few spreaded optically dense angular particles. In case of the DFDBA $\gamma-40$ SBF sample (Fig. 2e) fewer number of collageneous fibers and Ca-P globules. Upon higher magnification (Fig.2f) the globules manifest themselves again which look similar to those shown in Fig. 2a of the un-irradiated tissue with optically dense unshaped spots revealing several stages of crystallization.

\subsubsection{FT-IR:}

\section{i- Control (un-irradiated) DFDBA tissue:}

The FT-IR spectrum (Fig 3a) reveals few bands corresponding to both stretching phosphate at 1160 and $1080 \mathrm{~cm}^{-1}$ and bending phosphate at $670 \mathrm{~cm}^{-1}$ [15]. The stretching carbonate bands are detected at 1560 and $1541 \mathrm{~cm}^{-1}$ [16]. The bands at 3446, 2920 and $1655 \mathrm{~cm}^{-1}$ are assigned to the $\mathrm{OH}^{-}$stretching mode of vibration. The last band could be relevant to Amide $\left(\mathrm{NH}^{*}\right)$. These recorded bands are due to remnants of the demineralization process and prove that the tissue is not completely devoid of salts coinciding therefore with the findings of EDAX.

\section{ii- Irradiated Tissues:}

FT-IR spectrum of the tissue irradiated at $15 \mathrm{KGy}$ (Fig.3b) reveals initial pronounced increased O.D. of all the recorded bands. Then a trend of reduced O.D. in parallel with higher doses of $25 \mathrm{KGy}$ and $40 \mathrm{KGy}$ (Fig. 3c and e) excluding $30 \mathrm{KGy}$ could be detected. The spectrum of the $30 \mathrm{KGy}$ irradiated tissues unexpectedly exhibited several intense bands with substantial O.D values which amounted to almost 3 times that of the phosphate and hydroxyl bands as well as 4 times of $\mathrm{CO}_{3}^{2-}$ bands (Fig. $3 \mathrm{~d}$ ). The values of O.D. of all the detected bands of the sample irradiated with $40 \mathrm{KGy} \gamma$-dose approach that of un-irradiated one although still recording slightly higher values supporting the idea of annihilation.

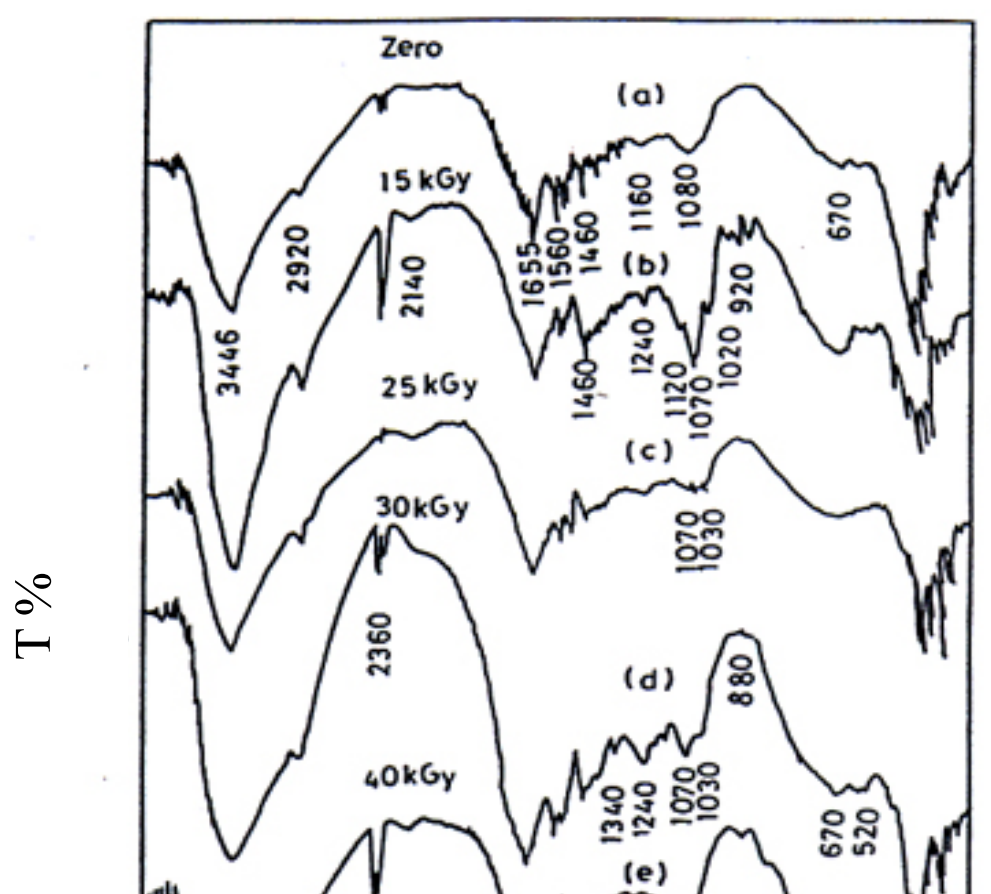


iii. Irradiated immersed tissue:

The $15 \mathrm{KGy}$ tissue reveals several new bands having slightly higher O.D. for all the recorded groups. Higher doses of 25 and $40 \mathrm{KGy}$ recorded reduced O.D of all bands. Unexpectedly, the O.D values of all bands for most of the groups of the $30 \mathrm{KGy}$-tissue are double that of pre-irradiated one as well as other irradiated tissues with higher or lower doses (Fig. 4). Such an increase in the O.D. could be connected with the densification of the inorganic remnants in the structure as well as cross linking of the collageneous part of the tissue reaching its maximum at $30 \mathrm{KGy}$ (Fig. 4). For $40 \mathrm{KGy}$ irradiated tissue the 
recovery observed is attributed to radiation defect annihilation, which could be due to migration and/or diffusion of irradiated produced vacancies to interstitial aggregates, a vacancy generation by dissolution, loop recovery effects due to irradiation created point defects as well as annihilation of vacancy clusters by self diffusion. Recently, Abdel Hamid et al. [17] demonstrated that primary phenomena associated with ion interaction are chain scission and/or aggregation, double bands and molecular emission. Such phenomenon is expected for the present collagenous matrices [18].

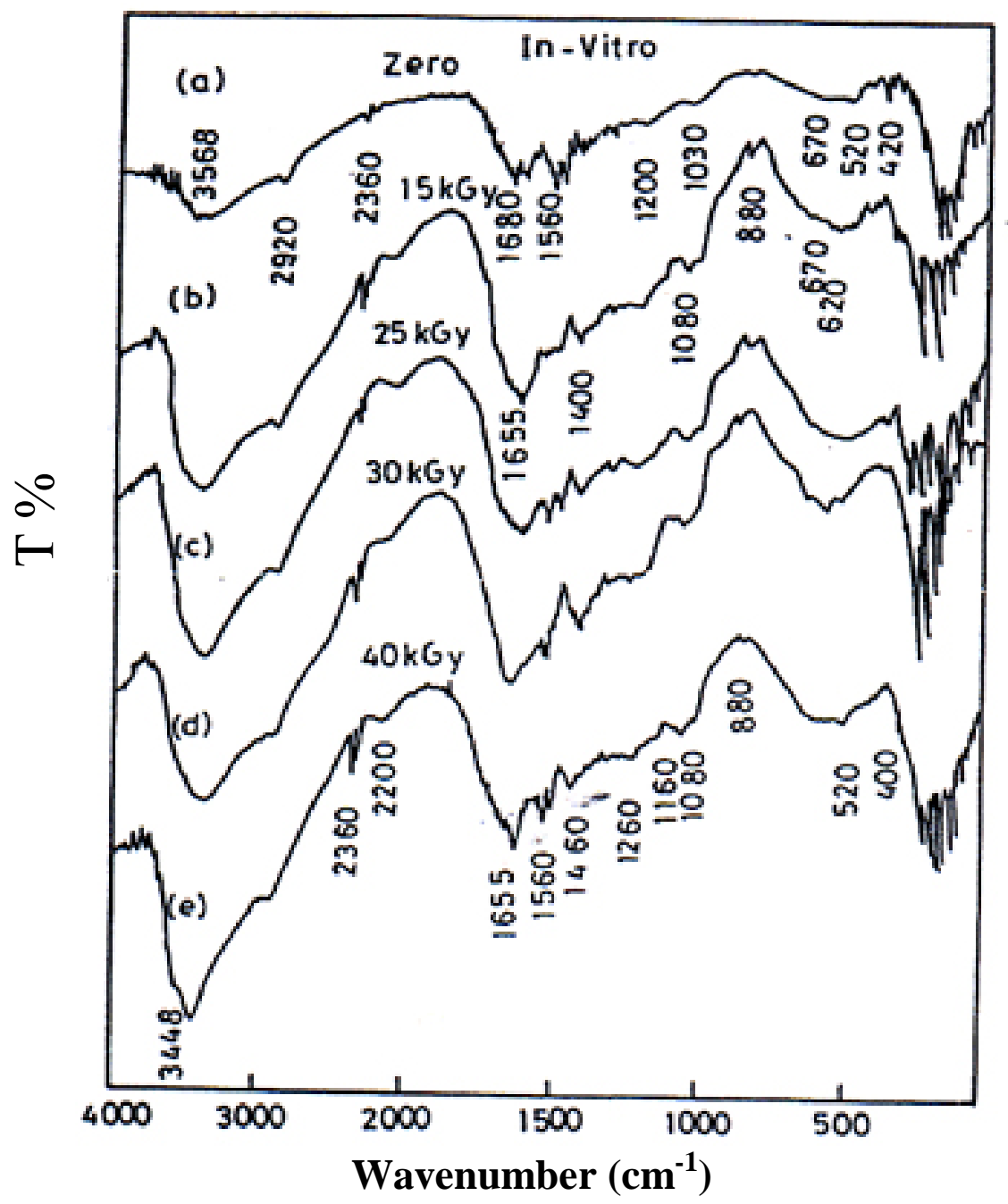

Fig. (4): FT-IR of 72 hours post-immersion (a) un irradiated DFDBA matrix (b) DFDBA irradiated with $15 \mathrm{KGy}$ (c) $25 \mathrm{KGy}$, (d)

The impligation off the presentresults on biolayer formation is predicted through calculating the values of ionic activity products $\left(\mathrm{Ca}^{2+}\right)$ (iP) for each 
immersion period of the control and the irradiated tissues with various doses (Fig. 5). The solution values of the irradiated tissues are lower than the (control) one at all the periods of immersion except at 6 hours due to reduced degradation of $\mathrm{Ca}^{2+}$ and parallel high deposition of iP ions. Their corresponding ionic $\mathrm{Ca}^{2+} / \mathrm{iP}$ ratios are also plotted in (Fig. 5) notifying that the $\gamma$-30 SBF sample having $\mathrm{Ca}^{2+} / \mathrm{iP}$ close to those of the control tissue at all periods of immersion. The data prove that rapid amorphous nucleation could occur due to the high $\mathrm{Ca}^{2+} / \mathrm{iP}$ ratios in the environment around the matrices especially at 24 and 48 hours according to the non-classical nucleation theory and explaining the FT-IR increased optical density (O.D.). According to Kim et al. [19] ionic concentration changes resulting variation in the ionic product gives rise to the apatite nuclei growth. Amjad and Zuhl [20] recently reported that initially precipitated calcium phosphate from aqueous solution was an amorphous calcium phosphate (ACP). Further ACP transformed to the more thermodynamically stable HA via the hydrolysis of octacalcium phosphate (OCP).

Finally, from the biochemical data at 72 hours post-immersion of DFDBA (zero-irradiation) in $\mathrm{SBF}$, the $\left(\mathrm{Ca}^{2+}\right)(\mathrm{iP})$ ionic activity product records the highest value compared with SBF and other irradiated forms with various doses (Fig.5). This predicts homogeneous nucleation of amorphous calcium phosphate (ACP) on its surface. It's $\mathrm{Ca}^{2+} / \mathrm{iP}$ ionic ratio has low value hence; brushite could be expected. In case of irradiated tissues the $\left(\mathrm{Ca}^{2+}\right)$ (iP) value are lower and its highest value appears at dose of $15 \mathrm{Kgy}$. Therefore, heterogeneous nucleation (direct crystallization) of ACP is to be expected. The irradiated tissues at 15 and $25 \mathrm{KGy}$ record medium value of $\mathrm{Ca}^{2+} / \mathrm{iP}$ ionic ratio which could lead to whitlockite formation. On the other hand, higher doses of 30 and $40 \mathrm{KGy}$ resulted in higher values of $\mathrm{Ca}^{2+} / \mathrm{iP}$ but due to lower activity product the formation of hydroxyapatite (HA) is precluded. At 72 hours immersion concerning the morphological features which assess the tissue irradiated with 15 KGy dose as the only tissue that record several stages of crystallization and being confirmed by FT-IR data are coinciding with the biochemical data. Although the tissues irradiated with 30 and $40 \mathrm{KGy}$ record higher $\mathrm{Ca}^{2+} / \mathrm{iP}$ ionic ratio, their lower activity product coincide with the recorded microstructure and FT-IR analysis.

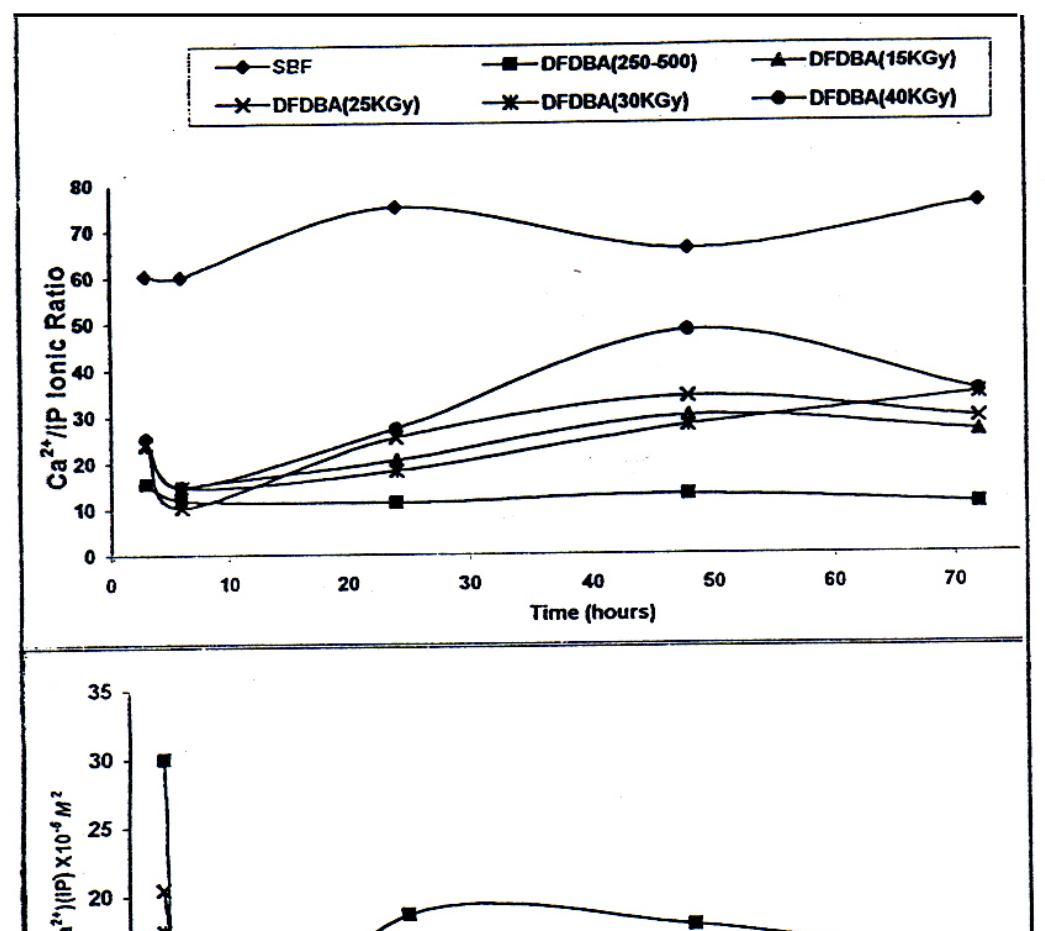




\section{Conclusions:}

(1) The trend of $\mathrm{Ca}^{2+}$ adsorption followed by iP release in SBF registered parallel release of both elements. This is attributed to the effect of freeze drying leading to denser structure.

(2) The FT-IR spectra agreed with the EDAX analysis detecting the Ca and P elements as well as the mineralization of phosphates as proved by SEM and biochemically. 
(3) The radiolytic products, annihilation phenomenon and FT-IR optical density (O.D.) are successfully correlated with the expected biolayer formation.

(4) An optimum sterilizing $\gamma$-dose of $15 \mathrm{KGy}$ is reached with maximum $\mathrm{Ca}^{2+}$ adsorption and reduced iP leaching due to optimum tight structure presenting several stages of calcium phosphate crystallization as confirmed by EDAX.

(5) The anomaly encountered with $30 \mathrm{KGy}$ dose is due to chain scission and/or aggregation as well as free radicals.

(6) A phenomenon of annihilation is encountered with $40 \mathrm{KGy}$ dose and attributed to migration and/or diffusion of irradiated produced vacancies to interstitial aggregation.

\section{References:}

1. S.S. Block, "Disinfection, Sterilization and Preservation".4th ed. Philadelphia: Lea and Febiger (1991).

2. GA. Driedzic, K. Ostrowski, W. Stachowicz, J. Michalik and W. Grzesik. Clin. Orthop: 272, 30 (1991).

3. N. Schwartz, H. Redl, A. Schiesser, G. Schlag, M. Thurnher, F. Lintner and H. Dinges Acta Orthop. Scand. 59(2), 165 (1988).

4. M. Reynolds and G. Bowers. J. Period. 67, 150 (1996).

5. ISO Designation $(1138 / 1,1137)$ "Radiation sterilization of health care products using gamma rays".

6. F.J. Buchanan, J.R. White, B. Sim and S. Downes, J .of Mat. Sci.: Mat. In Med. 12, 29 (2001).

7. G.R. Bozarth, H.L. Hutchinson, X. Li, X. Wang, R.P. Williams and C.M. Agrawal. American Academy of Orthopedic Surgeons. February 13(2002).

8. M. Wei, M. Uchida, H.M. Kim, T. Kokubo and T. Nakamura. Biomaterials 23(1), 167 (2002).

9. A.L. Oliveira, P.B. Malafaya and R.L. Reis. Biomaterials 24 (15), 2575 (2003).

10. P. Sepulveda, J.R. Jones and L.L. Hench. J. Biomed. Mater. Res. 61, 301 (2002).

11. K. Ishikawa, P. Ducheyne and S. Radin. J. of Mater. Sci.: Mater. In Medicine 4, 165 (1993).

12. Y., Leng, J. Chen, and S. Qu. Biomaterials 24, 2125 (2003).

13. L. Montanari, M. Costantini, EC. Signoretti, M. Santucci, M. Bartolomei, P. Fattibene, S. Onori, A. Faucitano, B. Conti and I. Geneta. J. Control Release 4:56 (1-3), 219 (1998).

14. Ravaglioli and A. Krajewski "Bioceramics: Materials. Properties. Applications". Chapman and Hall (1992). 
15. E.C. Victoria and F.D. Gnanam. Trends Biomater. Artif. Organs. 16(1), 12 (2002).

16. G.C. Koumoulidis, T.C. Vaimakis and T.C. Sdoukos. J. Am. Ceram. Soc. 84 (6), 1203 (2001).

17. H.M. Abdel-Hamid, R.M. Radwan, and A.H. Ashour,. Fifth Radiation Physics Conf., Cairo, Egypt (2000).

18. R.I. Mohamed, S.M. Abdou and S.M. El-Minyawi. Al-Azhar Bull. Sci. 2, 65 (2000).

19. HM. Kim, K., Kishimoto, F. Miyaji, T. Kokubo, T. Yao, Y. Suetsugu, J. Tanaka and T. Nakamura. J. Biomed. Mat. Res. 46, 228 (1999).

20. Z. Amjed and R.W. Zuhl. Phosphorus Research Bull. 13, 51 (2002). 